\section{Commentary: Aortic arch repair: The patient's anatomy and the surgeon's knowledge matter}

\author{
Ourania Preventza, MD, ${ }^{\mathrm{a}}$ and Joseph S. Coselli, $\mathrm{MD}^{\mathrm{b}}$
}

During open aortic arch replacement, various levels of hypothermia and other adjunctive techniques (ie, selective antegrade and/or retrograde cerebral perfusion) have been used as brain protection strategies. In addition, deep hypothermia may be beneficial for prolonged myocardial protection, which may be required during a complex arch repair. Each mode of brain and myocardial protection and distal organ perfusion has its proponents, all with a specific rationale for their approach.

In their article in this issue of the Journal, Kim and Matalanis ${ }^{1}$ elegantly describe the technique that they have popularized for replacing the aortic arch with minimal cerebral ischemia. The major advantages of their technique are avoiding excessive hypothermia and minimizing distal organ and cardiac ischemia. Very early on, the authors' team adopted "branch-first" total arch repair with a trifurcated graft. ${ }^{2,3}$ The individual head vessels are clamped for brief periods. During each head vessel reconstruction, the other 2 vessels are perfused and cardiac perfusion is maintained, which minimizes the total cardiac ischemic time. Distal organ perfusion is maintained throughout the operation. Moderate cooling to $28^{\circ} \mathrm{C}$, cardiopulmonary bypass, antegrade cerebral perfusion, and a rich collateral network between the arch vessels are usually necessary when this technique is followed.

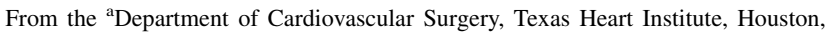
Tex; and ${ }^{b}$ Division of Cardiothoracic Surgery, Michael E. DeBakey Department of Surgery, Baylor College of Medicine, Houston, Tex. Disclosures: The authors reported no conflicts of interest.

The Journal policy requires editors and reviewers to disclose conflicts of interest and to decline handling or reviewing manuscripts for which they may have a conflict of interest. The editors and reviewers of this article have no conflicts of interest.

Received for publication Sept 30, 2020; revisions received Sept 30, 2020; accepted for publication Sept 30, 2020; available ahead of print Oct 9, 2020.

Address for reprints: Ourania Preventza, MD, Division of Cardiothoracic Surgery,

Michael E. DeBakey Department of Surgery, Baylor College of Medicine, BCM

390, One Baylor Plaza, Houston, TX 77030 (E-mail: preventz@bcm.edu).

JTCVS Techniques 2020;4:5-6

2666-2507

Copyright (C) 2020 The Authors. Published by Elsevier Inc. on behalf of The American Association for Thoracic Surgery. This is an open access article under the CC BY-NCND license (http://creativecommons.org/licenses/by-nc-nd/4.0/).

https://doi.org/10.1016/j.xjtc.2020.09.039
}

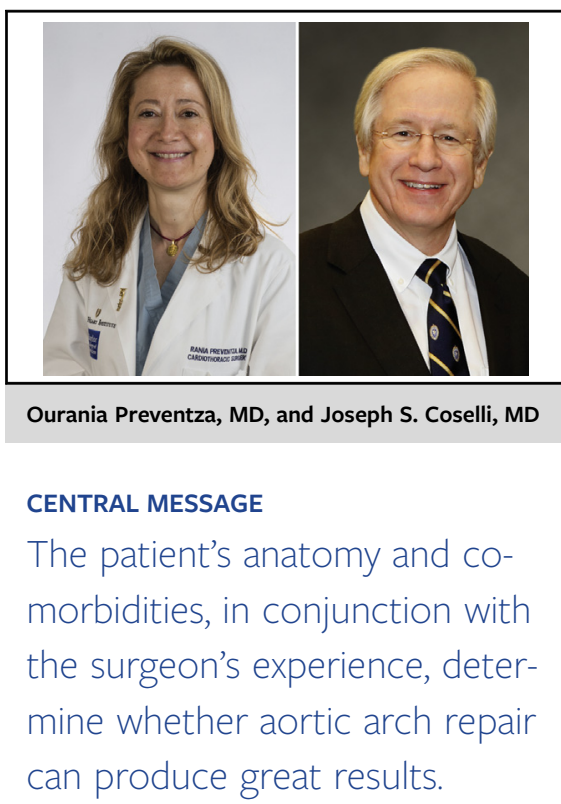

In 2002, Spielvogel and colleagues ${ }^{4}$ published their first series of 22 operations in which they used a trifurcated graft. Over the ensuing years, they modified their technique. ${ }^{5}$ The Spielvogel technique differs from that described by Kim and Matalanis mainly in that the debranching is done in reverse order (starting from the subclavian anastomosis when feasible), and cooling is to 18 to $22^{\circ} \mathrm{C}$.

There is no question that each technique has its merits, and that adapting to the individual patient's anatomy is important. Other arch repair techniques are also available depending on the patient's anatomy. ${ }^{6,7}$ In patients whose left subclavian artery is difficult to expose because of its lateral displacement, it may be necessary to delay its reconstruction until after the arch is opened and circulatory arrest (with antegrade cerebral perfusion) is initiated. Otherwise, preoperative or postoperative carotid-to-subclavian bypass or carotid-tosubclavian transposition, or intraoperative bypass from the left axillary artery to the trifurcated graft, may be required. In cases in which the 3 head vessels are close to one another, an island technique with a single patch anastomosis that includes all the head vessels may be appropriate, under deep or moderate hypothermia with unilateral or bilateral antegrade cerebral perfusion.

In addition, Kim and Matalanis advocate performing the distal anastomosis under circulatory arrest during arch replacement and after debranching is complete, using an endoluminal balloon or a clamp to control the descending thoracic aorta. Although these options are nicely laid out, they are easier said than done. Specific anatomy, such as 
isolated arch aneurysm in a patient with a normal descending thoracic aorta, is required for placement of a clamp or an endoluminal balloon in the descending thoracic aorta. In our experience, these cases are rare. Most of the time, the aneurysm extends distally to the descending thoracic aorta or the pathology otherwise makes the aforementioned maneuvers infeasible (eg, chronic aortic dissection with thrombus). Without a doubt, the patient's anatomy and comorbidities, in conjunction with the surgeon's experience, determine whether aortic arch repair can produce great results.

\section{References}

1. Kim M, Matalanis G. Technique and rationale for branch-first total aortic arch repair. J Thorac Cardiovasc Surg Tech. 2020;4:1-4.
2. Matalanis G, Galvin SD. "Branch-first" continuous perfusion aortic arch replacement and its role in intra-operative cerebral protection. Ann Cardiothorac Surg. 2013;2:194-201.

3. Matalanis G, Koirala RS, Shi WY, Hayward PA, McCall PR. Branch-first aortic arch replacement with no circulatory arrest or deep hypothermia. J Thorac Cardiovasc Surg. 2011;142:809-15.

4. Spielvogel D, Strauch JT, Minanov OP, Lansman SL, Griepp RB. Aortic arch replacement using a trifurcated graft and selective cerebral antegrade perfusion. Ann Thorac Surg. 2002;74:S1810-4; discussion S1825-32.

5. Tang GHL, Kai M, Malekan R, Lansman SL, Spielvogel D. Trifurcated graft replacement of the aortic arch: state of the art. J Thorac Cardiovasc Surg. 2015; 149(2 Suppl):S55-8.

6. Preventza O, Garcia A, Cooley DA, Haywood-Watson RJL, Simpson K, Bakaeen FG, et al. Total aortic arch replacement: a comparative study of zone 0 hybrid arch exclusion versus traditional open repair. J Thorac Cardiovasc Surg. 2015;150:1591-8; discussion 1598-600.

7. Preventza O, Coselli JS. Saccular aneurysms of the transverse aortic arch: treatment options available in the endovascular era based on a presentation at the 2013 VEITH Symposium, November 19-23, 2013 (New York, NY, USA). Aorta (Stamford). 2015;3:61-6. 